\title{
Animal Bite: Rabies and Beyond Rabies; A Review
}

\author{
Nitasha Sambyal ${ }^{1 *}$, Ankush Proch ${ }^{2}$, Inderpal Singh ${ }^{3}$ and Amit Challana ${ }^{4}$ \\ ${ }^{1}$ Department of Veterinary Public Health and Epidemiology, ${ }^{2}$ Department of Livestock \\ Production and Management, ${ }^{3}$ Department of Veterinary Surgery, ${ }^{4}$ Department of Veterinary \\ Anatomy, Khalsa College of Veterinary and Animal Sciences, Amritsar, India \\ *Corresponding author
}

\section{A B S T R A C T}

Increase in animal population has resulted in rise in animal bite cases and thus increase the potential for transmission of zoonotic diseases. That is why it is very important to consider

\section{Keywords}

Rabies, Animal bites, Dog,

Microbiology of animal bites, Biting mechanism of animals

\section{Article Info}

Accepted:

07 July 2019

Available Online:

10 August 2019 some factors while considering the likelihood of disease transmission which includes species of animal, type of injury, severity of injury, vaccination status, interval between incident and treatment, and various attributes of the injured person (age, underlying health, etc.). It is also important to have knowledge about the natural oral flora of the animal. As mouth cavity of animals is rich in microflora, which sets infection when inoculated in skin of victim. Most frequently isolated bacteria in animal bite other than Rabies are Pasturella spp., Streptococcus, Staphylococcus, Moraxella, Corynebacterium, Neisseria, Fusobacterium, Bacteroides, Posphuomonoa, Capnocytophagacanimorsus and Prevotella. But there is lack of understanding and a very few data is available on natural oral flora of animal, mechanism of animal bite and pathogenic significance of isolated organisms from bite wounds. Even though the available literature in this field if present mostly focused on case report of rabies, neglecting other diseases which are evenly fatal if untreated. Thus, in the present study, data from various sources has been summarized to emphasis on various infection other than rabies which are transmitted via animal bite including human and mechanism of animal bite. So that the infection cause by bite wound can be efficiently diagnose by a physician for its proper management.

\section{Introduction}

Animal bites continue to pose major public health challenges. The high risk group in animal bite cases comprises of veterinarians and animal owners, who should be more aware of bite risks and its consequences. Between $61 \%-68 \%$ of veterinarians suffer animal-related injury mainly dog and cat bites, kicks, scratches etc. resulting in hospitalization and loss of work hours (Langley et al., 1995; Gabel and Gerberich, 2002; Nienhaus et al., 2005). Children are the next most vulnerable group to attacks by animals. Nearly $40 \%$ are below 15 years of age and $78.6 \%$ were males (Ichhpujani et al., 2008). Children are typically bitten on the face, head and neck. Different locations for 
animal bites are represented in Table 1 . Injuries are complex in these body locations involving bony tissue injuries, intracranial complications and ophthalmologic lesions (Brogan et al., 1995). As calvarium of children is thin therefore it gets crushed during dog bite cases (Iannelli and Lupi, 2005). The wound mostly results in fracture of skull as well as pneumothorax, stroke, spinal cord trans-section, and tracheal or oesophageal lacerations. Thus makinganimal bites an important community health problem requiring surveillance by public health agencies across the world.

Animal bite wounds get infected with pathogenic bacteria that include wide variety of fastidious aerobic bacteria and approximately $50-80 \%$ anaerobic bacteria. It has been scientifically proved that the bacteria isolated from bite wound reflect the oral flora of biting animal and the microbes of their ingested prey. Most of these bacteria cannot be isolated in labourites, because many of these species may phenotypically similar to each other and some grow slowly and may be missed unless plates are incubated for a long time (Goldstein et al., 1978).

These wound get heal uneventfully and infectious complications are common. It is important that emergency physician should know about various diseases associated with animal bite and the tissue damage it caused. The severity of disease can be correlated with the biting mechanism. It has been reported that the inoculation of bacteria by cats are deeper than any other animals. If the fact is ignored than the anaerobic bacteria survives and condition becomes fatal.

India contributes the major share of animal bites as well as global deaths due to rabies. However, all these are preventable but for an effective prevention programme, it is important to understand the epidemiological behaviour of various animal bite diseases. As the data in this aspect is less thus, the present study emphasis the mechanism of bite and transmission of bite related diseases. Even an attempt is made to find the bacteriological status of the bite wounds including human bite by reviewing the literature using computer assisted database, research references from cited articles and personal experiences.

\section{Biting Status}

\section{World}

In America it has been estimated that 1 out of 2 American's during his or her lifetime is bitten by an animal that accounts for 4.7 million bites per year and the bite wounds account for approximately 0.5 to $1 \%$ visits to hospital emergency rooms (Goldstein, 1992). In an Annual Report (2001) by City of Fort Worth Public Health Department, almost forty-percent $(38.5 \%)$ of victims had high school education. More than $45 \%$ of bite victims were either the owner or acquainted with the owner. However, in most cases (73.7\%), the owner was not present at the time of the incident. Even the report suggests that, the majority $(78.6 \%)$ of bites were unprovoked. But in provoked cases, the situation was startling or awaking an animal $(8.9 \%)$. It was further reported that $32 \%$ of biting animals were more than 6 years old.

The highest biting frequency was found on Saturdays, followed by Tuesdays and Fridays. And the month vise graph showed increase biting frequency during early spring which peaks in summer. Only $5 \%$ and $60 \%$ of all bite wounds are complicated by infection, among them $20 \%$ to $50 \%$ of cat bites, $10 \%$ to $50 \%$ of human bites, $3 \%$ to $20 \%$ of dog and $25 \%$ monkey (Edwards, 2004).

\section{India}

In India 17.6 million annual animal bite cases are reported. Dog populations increased from 25.5 million in 1997 to 31.5 million in 2006, 
mostly are ownerless or unimmunized against rabies (livestock census data 2006) and cause 2.28 million dog bite annually or 0.1 bite per dog. But according to NICD 2000 in South India there is annual incidence of $2.06 \mathrm{dog}$ bites per 1000 of population. The household survey targeted 10 million population exposed to dog bites and rabies. It provides an estimate of 1.7 rabies cases per 100,000 and an estimate of 17,137 rabies cases in a one billion population, if paralytic form is $20 \%$ then the estimate increases to 20,565 or 2.06 cases per 100,000 .

It was concluded that number of rabies cases per feral dog in India are in between 2 and 3 per 100,000 persons, or between 93 and 136 cases per 100,000 dogs (Sudharshan, 1994). The highest incidence of rabies was in 10-44 years of age (72\%) (Sudarshan, 2005). But nothing can be said as data of rabies in animal are scanty, unreliable and controversial due to poor surveillance/reporting system. In U.S., the incidence of dog bite-related hospitalizations has been reported as $2.1 / 100,000$ persons and 1.6 to 2.0/100,000 adults $\geq 20$ years old. (Quinlan and Sacks, 1999)

Although a number of approaches are followed under evaluation to control rabies by managing dog population like dog movement restriction, reproduction and habitat control and dog removal. But one of such approaches, dog removal not only disrupts naturally established social organisation but also increases the contact rate, thus there is seen rise in population.

It was estimated that in India mortality due to rabies is 25,000 to 50,000 (Park, 1994), adults $(64.7 \%)$ among which $71.1 \%$ were males and $87.6 \%$ were from poor/low income group. Over $95 \%$ are caused by dog bites, (Sudharshan, 1994; Park, 1994; Rehman, 1996; Sehgal, 1996) among them $39.5 \%$ are by stray dogs and sites of bite were lower limb (56.2\%), upper limb (20.9\%) and hands (17\%). $79 \%$ of rabies victims did not receive any anti-rabies vaccination and if taken then course is incomplete (Sudharshan, 1994)

According to the anti-rabies department, Government Medical College-Jammu (2010), it has been estimated that from April 2009 to March 2010 out of total 4357 animal bite cases recorded, the number of dog bite cases were $3703(84.98 \%)$ followed by cat $(2.24 \%)$, cow $(3 \%)$ and 68 human bite cases.

\section{Biting Mechanism}

Anatomy of the teeth and the strength of the jaws reflect in the nature of injuries caused by the biting animals which is directly proportional to its severity. On the basis of type of injuries caused by the biting animals, animal bites can be categorised into 3 typesavulsion (when skin is torn from underlying tissue and bone), laceration (most severe tear of underlying tissues with irregular edges) or puncture (teeth penetrating the skin and underlying structure) (Goldstein, 1992).

\section{Canine}

Teeth of canines are large, broad and sharp. Jaws have powerful masseter-pterygoid complex muscles. This physical design of the mouth of the canine is associated with avulsion and laceration type of bites (Chambers and Payne, 1969). Therefore dog causes crushing injuries with direct structural damage to underlying vasculature, tendons, nerves, or joints (Benson et al., 2006). Although all breeds of dog are capable of severe damage but the large brachiocephalic dogs have a greater biting force, compared with that of small dolichocephalic dogs. Breeds of dog which are more notorious for attack without provocation are pit bull breed, followed by Rottweilers, German Shepherd 
Dogs and Chow Chows (Sacks et al., 1996).

\section{Cat}

The biting style of cat is different; it first bites and then holds their prey until they are motionless (Talan et al., 1999). Because of their characteristic sharp, elongated, needlelike teeth (Bradley, 2002), the bite is typically deep puncture wound which pierce underlying structures, including ligaments, bone, joint capsule, tendon sheath, neurons, and vascular structures (Myers, 2003).

\section{Other animals}

Bite by mice, rats and snakes tend to cause puncture wounds.

\section{Human}

The bite resembles dog bite with abrasions and laceration being more common than punctures.

High risk animals are Bats, Raccoons, Skunks, Foxes, Bears, Opossums, Weasels, Wolves and Woodchucks. Whereas animals which pose less risk to human are Immunized dogs, cats, and ferrets, besides Squirrels, Hamsters, Rats, Mice, Rabbits, Hamsters, Chipmunks, Guinea pigs, Gerbils etc. pose little risk.

Among the various types of animal bite wound, the highest incidence of infection is seen in puncture wound as they get quickly sealed. Thus produce an environment for the growth of anaerobes. Wounds punctured by cats inoculate the microbes deep into the tissues which remain unnoticed and cause infection.

\section{Microbiology}

Mammalian mouth contains approximately 100 million microbes per $\mathrm{ml}$ of saliva belonging to over 200 species of facultative microbes and obligate anaerobes. Some recognized microbes are mentioned in Table 2.

\section{Dog and cat}

Most frequently isolated aerobic bacteria are Pasturella spp. (50\% Pasturella canis in dog bites and $75 \%$ Pasturella multocida subspecies multocida and septic in cat bites), next most commonly identified species are Streptococcus (46\% cases), Staphylococcus (46\% of dog bites and 35\% of cat bites), Moraxella, Corynebacterium, and Neisseria. The most commonly identified anaerobes are species of Fusobacterium, Bacteroides, Posphuomonoa, Capnocytophaga canimorsus and Prevotella (Talan et al., 1999).

\section{Human bites}

They transfer more bacteria to his victim as compared to dog or cat bites as human mouth has higher population of resident bacteria (Smith et al., 2000). The microbial difference of human bite in compare to dog and cat bite is that in human bite there is presence of Eikenella corrodens, the absence of $P$. multocida, and a higher incidence of $\beta$ lactamase-producing organisms. Rare cases of Streptococcus pyogenes necrotising fasciitis after human bites have been reported by Wienert et al., (1999).

\section{Alligator}

Its bite wound most frequently consist of Aeromonas hydrophila fallowed by Enterobacter agglomerans, Citrobacter diversus, Proteus spp., Pseudomonas spp., Serratia spp., and Clostridium spp. (Greenberg, 1999).

\section{Snakes}

Wound caused by snakes have high rate of 
infection by enteric gram-negative bacilli. The reason may be, the way snake eats the pray, the head of prey is swallowed first and the prey's fecal flora subsequently colonizes in the snake's mouth. Even though the venom of snake is sterile and after the bite causes extensive necrosis of the tissue. Thus providing an optimal environment for growth of inoculated organisms such as Pseudomonas aeruginosa, Proteus spp., Salmonella arizonae, Aeromonas spp., Vibrio vulnificus, Bacteroides fragilis and Clostridium spp. Gram-positive skin flora are also frequently isolated that include staphylococci (Hsieh and Babl, 1999).

\section{Horse}

The bite infection by horses mostly caused by $S$. anginosus and $S$. mutans producing extensive gas in the tissues. Other isolated organisms are Actinobacillus lignieresii, $S$. aureus, Neisseria spp., E. coli, Pasteurella spp., Bacteroides ureolyticus, B. fragilis, Prevotella melaninogenica, $P$. heparinolytica (Goldstein, 1994; Abrahamian et al., 2004).

\section{Shark}

Their bite mostly contains vibrio spp. It also includes A. hydrophila and S. aureus.

\section{Other marine animal}

The bite wounds are infected with $A$. hydrophila, B. fragilis, Chromobacterium violaceum, Clostridium perfringes, $E$. rhusiopathiae, E. coli, Mycobacterium marinum, P. aeruginosa, Salmonella enteritidis, S. aureus, streptococci, Vibrio vulnificus, Vibrio carchariae, Vibrio damsela, Vibrio parahaemolyticus, and Peptostreptococcus spp. (Brook, 2003; Murphey et al., 1992). Infection caused by animal bites develops at the site of the wound. Microbes recovered from the adjacent tissue of bite wounds suggests that the infection is transmitted from the oral flora of the biting animal (Iannelli and Lupi, 2005).

Although the severity of infection at the site of animal bite is not only depends upon the oral flora of the person or animal inoculating the wound. But it also depends upon the anatomic location and structures damaged by the animal bite, microbial contamination of the wound from the environment or skin, and the time elapsed since the injury.

\section{Some important pathogens}

Although rabies is an important animal bite disease but there are many other diseases which must be considered as they are evenly fatal if untreated. An attempt is made to described some of these diseases.

\section{Rabies}

It is the fatal neurological infection primarily of wild animals but also found in domestic animals from where it spread to humans by direct contact of saliva of rabid animal to mucous membrane, wounds or via bite. Even spread by inhalation of aerosol originating from bat caves.

It is caused by neurotropic, genus Lyssa virus. This genus includes the classic rabies virus, two European bat lyssa viruses, an Australian bat lyssa virus, and the African Duvenhage virus. They all produce a similar fatal encephalomyelitis in humans, known as rabies.

In $90 \%$ of the cases it is transmitted to human by the close association of domestic animals (Chhabra and Ichhpujani, 2003). There is no human to human transmission, with the exception of eight cases resulting from corneal graft implants and three from solid organ transplantation. There was one suspected case 
where virus transmits via mother to a breastfed infant (Dutta, 1998). Transplacental infection occurs in animals but has not been reported in humans. It is endemic in many parts of the world. India reports around 30000 deaths due to rabies (Chomel, 1993) among them $30-50 \%$ were children reported by Rotivel et al., (1998). But in the latest 2011 survey death toll reduces to 233 times due to public awareness and vaccination of the street dogs. Although in U.K. 1920 it was reported by pounder (2003) that rabies was eradicated but still in past 20 years 12 people died due to this.

Rabies virus cannot penetrate the intact skin and can be inactivated by ultraviolet rays and does not persist in environment. There-fore coming in contact with the environment around a rabid animal such as bedding or water bowls does not present a risk. It is not a true zoonosis as some infected animal die from infection (Sikes, 1962). In a survey done by Eng and Fishbein (1990), stated that rabid dogs die within 8 days of becoming infected.

\section{Clinical manifestation}

Symptoms in the infected animal are characterized by increased aggression, ataxia, lethargy, or excess salivation; nocturnal animals may become active during the daytime. After bite the virus multiplies in the cells at the site of bite subsequently ascends centripetally to the CNS via peripherals nerves. In the neurons of brain it replicates and then transmitted centrifugally and deposit in body tissue including salivary glands via efferent nerves. Incubation period varies with the site of bite i.e. between 30-90 days even upto 7 years (may be 14 years exceptionally). It is shortest when bite is on head and neck (around 15 days) but prolonged when the bite is on extremities. First symptom is itching, pain or paraesthesia at the site of healed wound. Patients often complained of encephalopathic syndrome that can be of two form- furious or paralytical form. Furious rabies is manifested by irritability, agitation, hyperaesthesia and autonomic disturbances (disorders of blood pressure, hypersalivation, and sweating). Hydrophobia is the pathognomonic symptom which is spasm of inspiratory muscle, painful laryngospasm and fear of swallowing. Initially it is while drinking water but later even on slightest stimulus or mention of water and end in aerophobia i.e. extension of the back and arms fallowed by generalised convulsion or cardiorespiratory arrest.

In untreated cases hydrophobic spasm is preceded by death or a generalized flaccid paralysis and death in a week. Paralytic form is seen in $20 \%$ of human cases and occurs after bites of vampire bats (Delpietro and Russo, 1996) or bite of vaccinated individual.

A flaccid paralysis develops with pain and fasciculation of the affected muscles, paraplegia and sphincter disturbances followed by paralysis of the respiratory and deglutive muscles. Hydrophobia is rare but spasms of the laryngeal muscles may occur in the terminal phase. Without treatment patients may survive for up to 30 days.

It can be misdiagnose with tetanus, as a wound on head and neck can cause cephalic tetanus causing trismus (facial stiffness and pharyngeal and laryngeal spasms) followed by asphyxia or aspiration. But can be distinguish as its incubation period is short (15 days), persistent muscle spasms and absence of meningoencephalitis.

According to the Association for Prevention and Control of Rabies in India (APCRI), India has the world's highest number of dog-bite cases resulting in 80 per cent of the world's rabies cases. They have even reported that, mainland of India is endemic and enzootic to 
rabies and the islands of Andaman \& Nicobar and Lakshadweep are rabies free and to ensure a Rabies Free India by 2020 a coordinated 'National Rabies Elimination Programme was launched (Sudarshan, 2005).

\section{Bergeyella zoohelcum}

It is a zoonotic pathogen, indigenous to dog and cat. It is reported in 38-90\% nasal, gingival scrapings and oral fluid of dog (Decostere et al., 2002; Reina and Borrell, 1992). It is transmitted to human after a dog or cat bite, but Kivinen et al., (2003) also found its transmission via close contact with cats. It was referred by Centers for Disease Control and Prevention (CDC) as group IIj organism. In Holmes et al., (1986) proposed its name as Weeksella zoohelcum but in 1994 Vandamme et al., (1994) proposed a new genus, Bergeyella zoohelcum.

\section{Morphology}

B. zoohelcum is a non-fermentative, Gramnegative, rod-shaped, non-spore-forming, nonmotile aerobic bacterium that typically grows well on blood agar with characteristic colonies as circular, shiny, and smooth with entire edges (Holt et al., 1994) but no growth on MacConkey's agar. B. zoohelcum is oxidase, catalase, and indole positive. At present, $B$. zoohelcum is the only representative of the genus Bergeyella.

Botha et al., (1998) linked food as source of Weeksellaand Bergeyella like bacteria. But on the other hand $W$. virosa, is a female urogenital pathogen and has been reported in healthy women $(2 \%)$ and up to $15 \%$ in women with a high rate of sexual activity (Mardy and Holmes, 1988).

\section{Clinical manifestation}

After exposure to dog bite it causes pneumonia, meningitis (Bracis et al., 1979;
Grimault et al., 1996), septicemia, leg abscess and tenosynovitis (Isotalo et al., 2000; Reina and Borrell, 1992). Although it is an opportunistic pathogen with low virulence but to avoid complication of endocarditis the infection should be promptly treated (Kivinen et al., 2003).

\section{Treatment}

Goldstein et al., (1999) reported that $W$. zoohelcum (Bergeyella) isolates are sensitive to gatifloxacin at $0.016 \mathrm{~g} / \mathrm{ml}$ and to the linezolid $(2 \mathrm{~g} / \mathrm{ml})$

B. zoohelcum has host deversity, Kroes et al., (1999) reported it as commensal of human oral flora. Woo et al., (2003) suggested that there could be misidentification of $B$. zoohelcum as Riemerella anatipestifer if the MicroSec 500 16S rDNA-based identification system (which uses the first 527 bases of the $16 \mathrm{~S}$ rRNA gene) is used. Even the ecological habitat (regardless of the host) of $B$. zoohelcum is related to the oral environment. Thus in the past, there is possibility that fastidious strains of B. zoohelcum from animal bite wounds was not reported.

\section{Capnocytophaga}

It is from family flavobacteriaceae and is in the Flavobacterium- Cytophagar RNA homology group as described by Mandell et al., (2005) and Vandamme et al., (1996). Formerly Capnocytophaga canimorsus was originally isolated from the human oral cavity and described in 1956 by De Cadore et al., (1956) it was isolated from the blood and spinal fluid of dog bitten patient and was known as dysgonic fermentor-2 or DF-2 (Bobo and Newton, 1976; Brenner et al., 1989). But its current name Capnocytophaga (means "eater of Carbon dioxide") canimorsus (means "dog bite") was given in 1989 by Brenner et al., (1989). 


\section{Morphology}

It is a fastidious, slow growing, an anaerobic, non-spore forming, Gram-negative, spindle shaped bacteria. It is catalase, oxidase, and indole negative. Many strains of the bacterium produce a yellow-brown pigment.

Being fastidious, other rapidly growing bacteria retard its growth, so colonies become apparent only after prolonged incubation of 48 to $72 \mathrm{~h}$ (Holt et al., 1979; Leadbetter et al., 1979; Socransky et al., 1979). Although the organism grows slowly in blood cultures (6 days), a rapid interim diagnosis can be made by Gram staining the buffy-coat preparations (Abrahamian et al., 2004).

It has been isolated from the oral cavity of both human and canine species and is the important etiology of localized juvenile periodontitis (Newman et al., 1976). Valtonen et al., (1995) have also reported few cases of C. canimorsus from cat bite infection.

\section{Clinical manifestation}

Small proportion of untreated dog bite victims develops septicemia, subsequent multi-organ failure and ultimately death. But Brenner et al., (1989) and Winkler (1977) suggested that the predisposing factors for severe infection are splenectomy, alcoholism, liver disease, corticosteroid therapy, lymphoma or leukaemia patient, chronic lung diseases and immune-compromised patient who sustain a $\mathrm{dog} / \mathrm{cat}$ bite. They are the high risk groups which need more attention.

Symptoms after bite appear within 1 to 8 days (Hore, 2001). The patient becomes lethargic, tiredness, listlessness and subsequent fevers, rigors and fulminant sepsis with disseminated intravascular coagulation (DIC) with septicemia (34 to $36 \%$ of cases), meningitis, septic arthritis, endocarditis, renal failure, acral gangrene (15\% of cases), disseminated purpura (37\% cases) with erythema and rare ocular infection (Brenner et al., 1989; Lion et al., 1996).

Even necrosis of the extremities followed by multi-system organ failure is also seen (Hore, 2001). Most of the patients also suffer from mucosal ulcerations and gingival bleeding.

It is not always important that infection occurred via bite; even the lick of dog at superficial burn can cause entry of the bacterium. Patients commonly associated with gastrointestinal complains including abdominal pain $(26 \%)$, vomiting $(31 \%)$, and diarrhea (26\%) (Pers et al., 1996).

Fischer et al., (1995) reported that, although the bacterium is present in all dog wounds but still infection is rare. It is due to the fact that it is a fastidious bacterium with low virulence which is even susceptible to post bite prophylaxis antibiotic. Therefore most of the infection occurred in immune-compromised patients.

In a review, Lion et al., (1996) listed that 33\% of systemic infections occurred in asplenic patients, 24\% in alcoholics, and 5\% in immuno-compromised patients and $41 \%$ of infections in patients without any known risk factor. During systematic infection there is high mortality about $20 \%$.

Keeping in view the risk group, it is important to inform the physicians about the history of splenectomy or other immune-compromising conditions of the patient after a dog bite as they are the predisposing conditions for $C$. canimorsus infection.

\section{Treatment}

C. canimorsus infection can be treated by penicillins G (Jolivet-Gougeon et al., 2000), 
imipenem, erythromycin, vancomycin, clindamycin, third-generation cephalosporins, chloramphenicol, rifampicin, ofloxacin, ciprofloxacin, doxycycline and quinolones (Hore, 2001). But it is typically resistant to aztreonam, trimethoprim-sulfamethoxazole and aminoglycosides (Hore, 2001).

\section{Pasteurella species}

The bacterium has been reported by Woolfrey et al., (1985) from the fang flora of $90 \%$ of large feline population. Human infection occurs after bite, scratch or direct contact with saliva of infected animals, more important in immuno-compromised human. Pasteurella multocida subspecies multocida and septica were isolated from systemic infections by O'Neill et al., (2005), caused by a bite or licking of wounds by dogs and cats.

\section{Morphology}

It is pleomorphic Gram negative, non-spore forming, cocobacillus. It is sugar fermentative, non-motile, facultative anaerobic bacteria. It shows Bipolar staining by the Giemsa, Wright or Romanowsky staining methods. It gives catalase, oxidase, nitrate reduction and indole positive and urease negative test. Selective colonies canbe kept in BBL-soy-trypticase, Difco-tryptose-starch-Gibco-dextrosis. Colonies on Brain Heart Infusion (BHI) agar and Nutrient agar shows Mucoid, sticky convex colonies of 2-3 mm diameter. On blood agar colonies are translucent grayish or yellowish green without haemolysis and no growth on MacConkey agar.

\section{Clinical manifestations}

Incubation period for infection is 24 hours with the appearance of erythema, swelling, tenderness and drainage at the site of the bite. Infection remains localized to the inoculated wound with cellulitis and abscesses, but direct extension to surrounding tissues may occur resulting in lymphangitis, regional lymphadenopathy fallowed by bacteremia with metastatic foci causing osteomyelitis, arthritis, cirrhosis, diabetes, hematologic malignancies, neoplasms and immunosuppression (Smith et al., 2000; Weber, 1984; Morris and McAllister, 1992).

Licking of face and ear by cat and dog is associated with rheumatoid tenosynovitis, sepsis and meningitis, while licking of ulcers of the owners legs can results in brain abscess, pneumonia and endocarditis (Weber, 1984). Infection via aerosols route causes tonsillitis, sinusitis, epiglottitis, under-mandible cellulitis (Ludwig's angina).

Early diagnosis is important especially for young and elderly people as well as in immuno-suppressed patients including the pregnant woman (Jordan et al., 2006; Kaufman et al., 2005). Although serological tests are not used frequently for diagnosis but still recent exposure can be indicated by higher titration (from 1/160 up to $1 / 1280$ or higher ones) obtained through hemagglutination reaction.

\section{Treatment}

Drug of choice is penicillin and ampicillin. Cefuroxime and cefpodoxime have better invitro activity than other cephalosporins. Nafcillin, dicloxacillin, cefazolin, cefaclor, cefadroxil, and cephalexin fallowed by Clindamycin and the aminoglycosides are resistant to Pasteurella species (Goldstein et al., 1988).

Antibiotics treatment is used in patients undergoing steroids treatment or in patients with lesions on the face and hands, immunocompromised, diabetic etc. 
(Source for Table 1: City

of Fort Worth Public

Health Department,

Animal bite prevention

program: Annual

Report-2001)

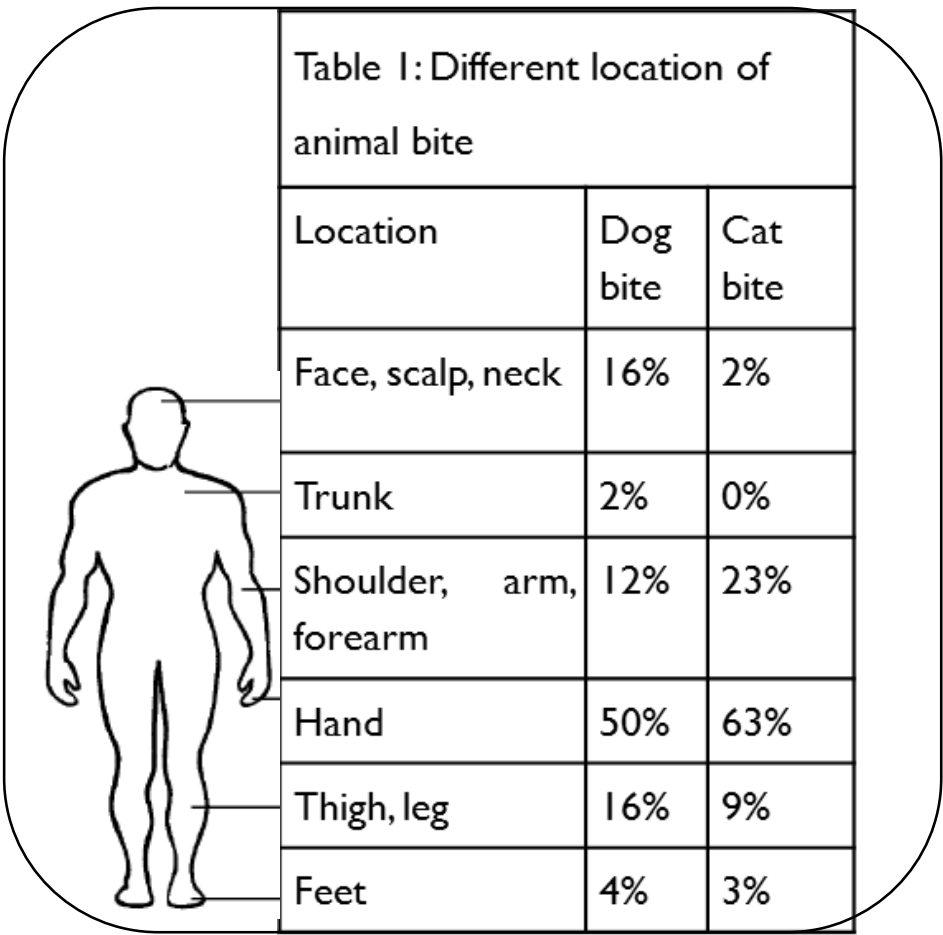

Table.2 Some recognised microbes detected in various biting species

\begin{tabular}{|c|c|c|c|c|}
\hline S. no. & $\begin{array}{l}\text { Biting } \\
\text { Species }\end{array}$ & Biting frequency & Biting force & Microbes \\
\hline 1. & Dog & $80-90 \%(82.4 \%)$ & $\begin{array}{l}320 \text { lbs (wolf- } \\
400 \quad \text { lbs), } \\
\text { mastiff-500 lbs }\end{array}$ & 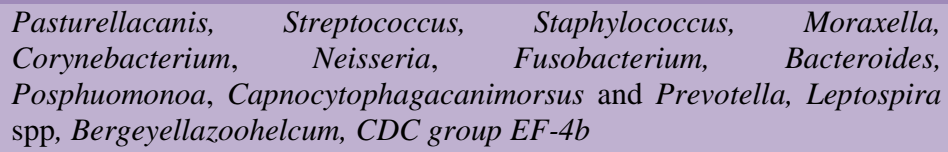 \\
\hline 2. & Cat & $5-15 \%(16.2 \%)$ & $20 \mathrm{lbs}$ & $\begin{array}{l}\text { Pasturellamultocida subspecies multocidaand septica, Streptococcus, } \\
\text { Staphylococcus, Moraxella, Corynebacterium, Neisseria, Fusobacterium, } \\
\text { Bacteroides, Posphuomonoa, Capnocytophagacanimorsus and } \\
\text { Prevotella, Bartonella henselae, Tularensis, Comamonas }\end{array}$ \\
\hline 3. & Human & $1 \%$ & $120 \mathrm{lbs}$ & $\begin{array}{l}\text { Eikenella corrodens, Streptococcus pyogenes, Porphyromonas, hepatitis } \\
B\end{array}$ \\
\hline 4. & Alligator & Rare & $2500 \mathrm{lbs}$ & $\begin{array}{l}\text { Aeromonas hydrophila, Enterobacter agglomerans, Citrobacter diversus, } \\
\text { Proteus spp., Pseudomonas spp., Serratia spp., and Clostridium spp. }\end{array}$ \\
\hline 5. & Snakes & & $\begin{array}{l}\text { Phyton: 200lbs } \\
\text { Anaconda: } \\
600 \text { lbs }\end{array}$ & $\begin{array}{l}\text { Pseudomonas aeruginosa, Proteus spp, Salmonella arizonae, Aeromonas } \\
\text { spp., Vibrio vulnificus, Bacteroides fragilis and Clostridium spp. }\end{array}$ \\
\hline 6. & Horses & & & $\begin{array}{l}\text { S. anginosus, S. mutans, Actinobacilluslignieresii, S. aureus, Neisseria } \\
\text { spp., E. coli, Pasteurella spp., Bacteroides ureolyticus, B. fragilis, } \\
\text { Prevotellamelaninogenica, P. heparinolytica. }\end{array}$ \\
\hline 7. & Sharks & & $600 \mathrm{lbs}$ & Vibrio spp., A. hydrophilaand S. aureus. \\
\hline 8. & Rat & $2 \%$ & 360 lbs & Streptobacillus moniliformis, Spirillum minus \\
\hline 9. & $\begin{array}{l}\text { Other } \\
\text { marine } \\
\text { animals }\end{array}$ & & & $\begin{array}{l}\text { A. hydrophila, B. fragilis, Chromobacteriumviolaceum, Clostridium } \\
\text { perfringes, E. rhusiopathiae, E. coli, Mycobacterium marinum, P. } \\
\text { aeruginosa, Salmonella enteritidis, S. aureus, streptococci, V. vulnificus, } \\
\text { Vibrio carchariae, Vibrio damsela, Vibrio parahaemolyticus, and } \\
\text { Peptostreptococcusspp. }\end{array}$ \\
\hline
\end{tabular}




\section{Cat scratch fever}

It is also known as benign inoculation lymphoreticulosis, cat-scratch Syndrome, Cat adenitis, Cat-claw fever. It is mild to severe disease that affect human, although cat carries the bacteria but do not get sick. It only transmits the infection via bite or scratch. It is thought that cat flea (Ctenocephalides felis) can also transmit the bacteria to cats and can act as possible vectors in transmitting the bacteria directly to humans.

\section{Etiology}

It is caused by Bartonella henselae bacterium (after A.L. Barton, a Peruvian physician who first described the germs). Earlier it was thought to be by Afipiafelis and then a rickettsia Rochalimaeahenselae. It is a small, Gram-negative, pleomorphic with arrangement in the forms of $\mathrm{Y}$-shape, chains or clumps, intracellular bacilli located in capillary walls, near follicular hyperplasia and inside micro-abscesses with Warthin-Starry silver stain.

\section{Clinical manifestation}

The disease is seasonal in temperate climates, with most cases occurring during winter. Whereas no seasonal differences seen during hot climates. Approximately $75 \%$ of the cases occurred in children. Incubation period is between 7 to 20 days which is characterized by a papule or a cluster of papules at the site of inoculation, followed by regional lymphadenopathy without lymphangitis within 3-30 days. Primary lesions are seen at the point of inoculation i.e. partially healed ulcers surrounded by an erythematous area or erythematous papules, pustules, or vesicles. Lymphadenitis is generally unilateral appearing in the epitrochlear, axillary or cervical lymph nodes or in the femoral and inguinal lymph glands. Swelling in the lymph glands is painful with suppurations which persist for few weeks to few months. It is also associated with pneumonia, pharyngitis, thyroiditis, encephalitis, hepatomegaly, splenomegaly, optic neuritis, cerebral arteritis and endocarditis. During systemic infection, fever is short-lived fallowed by chills, anorexia, malaise, generalized pain, vomiting, and stomach cramps. In rare occasion morbilliform cutaneous eruptions occur.

Although there is no sequel of the disease but in few cases complication do arise like Parinaud's oculoglandular syndrome, encephalitis, osteolytic lesions, and thrombocytopenic purpura. In Parinaud's oculoglandular syndrome, the route of entry is via conjunctiva or eyelids. It occurs when a person rubs his eyes after picking up infected cat. The conjunctival lesion heals in 1-3 weeks without causing damage to eye (August, 1988).

\section{Treatment}

Gentamicin and doxycycline or oral administration of erythromycin proven successfully. It is recommended that immunesuppressed patients should avoid contact with kittens and young cats, if they do get bitten or scratched, they should seek medical attention as soon as possible.

\section{Rat bite fever}

It is a rare systemic infection caused by Streptobacillus moniliformis present normally in the nasopharyngeal flora of rodents, gerbils, mice and other rodents and Spirillum minus (In Asia, known as sodoku) present in infected eyes of rats. In North America Streptobacillus moniliformis is also known as Streptothrix murisratti, Nocardia muris, Actinomyces muris, Actinobacillus muris, Proactinomyces muris, Haverhillia multiformis and Asterococcus muris. 


\section{Morphology}

Streptobacillus moniliformis is a non-motile, pleomorphic, microaerophilic bacillus commonly found in the oropharynx of wild rats. Spirillum minus is a small, thick, Gramnegative, motile spirochete with bipolar flagellar tufts (two or three turns).

The bacteria is spread through rat bit $(10 \%$ cases), scratch, ingestion of food or water contaminated with rat feaces and urine (known as Haverhill fever when organism is Streptobacillus moniliformis), ingestion of unpasteurized $S$. moniliformis contaminated milk or via handling rats (pet rats owners, laboratories) and also by aerosol. Cases have been reported that the infection occurred by bite of cats, dogs, ferrets, and weasels (may be they are originally infected by rodents).

\section{Clinical manifestation}

Infection caused by Streptobacillus moniliformis is known as streptobacillary. Although incubation period is 3 to 10 days but before symptoms appear, bite wounds get healed without inflammation. Symptoms include fever, vomiting, headache, muscle pain, joint pain and rash. After 2 to 4 days followed by morbilliform petechial rash on extremities i.e. hands and feet (in $75 \%$ of patients) but in $50 \%$ of cases it is followed by migratory polyarthalgia or arthritis affecting the knees, shoulders, elbows, wrists, or hands which persist for years. Other serious complications including tenosynovitis, endocarditis, pericarditis, myocarditis, hepatitis, nephritis, meningitis, pneumonia, sepsis, and focal organ abscesses can also occur. Diarrhea is seen in infants and children causing weight loss.

Haverhill fever is associated with severe nausea, vomiting, and pharyngitis. Complications include endocarditis, abscesses in the brain, tenosynovitis, pericarditis, myocarditis, hepatitis, nephritis, meningitis, pneumonia, sepsis, and focal organ abscesses. The mortality rate is $7 \%$ to $13 \%$ and $53 \%$ in endocarditis.

Spirillary is the infection caused by Spirillum minus with incubation period of 21 days. It is characterized by a relapsing fever, ulceration or eschar at the site of the bite wound, lymphadenopathy and lymphangitis. A roseolar-urticarial rash develops in $75 \%$ cases. Fever reappears in 2 to 4 cycles for four to eight weeks. Complication includes arthritis, endocarditis and nephritis. It rarely occurs in U.S., but is present in patient who had travelled to Asia.

Although rats are asymptomatic to $S$. moniliformis and S. minus infection, but can suffer from otitis media and can be present in subcutaneous abscesses as secondary invader. In mice infection develops polyarthritis, subcutaneous or hepatic abscesses, Conjunctivitis, photophobia, cyanosis, diarrhea, anemia, hemoglobinuria. Brown crusts can occur over the mammae of nursing females. Chronic arthritis, with swelling of the limbs or tail, may be a sequela. Deformation, ankylosis, or posterior paralysis, kyphosis, and priapism occur. Abortions and stillbirths have also been reported.

Guinea pig: S. moniliformis is associated with granulomatous pneumonia or cervical lymphangitis. Non-human primates described Septic arthritis and endocarditis. Turkeys and a tawny owl: Arthritis with infected feet was reported in the U.K.

\section{Treatment}

Drug of choice is Penicillin given @ (400,000- 600,000 units IM bid), or penicillin $\mathrm{G}$ intravenously for seven to ten days. For uncomplicated cases, oral penicillin or 
tetracycline may be effective therapy. Antibiotic for $S$. moniliformis include Cephalosporins and Vancomycin. Erythromycin has variable activity against $S$. moniliformis.

\section{Porphyromonas}

It is present in the gingival pocket of human and animals (Dzink et al., 1988) and thus can be isolated from bite wounds of $28 \%$ victims (Citron et al., 1996). They were previously classified in the genus Bacteroides (Shah and Collins, 1988). The results indicate that vitamin $\mathrm{K} 1$ and hemin are important factors for the growth of most strains of Porphyromonas spp. Previous studies have indicated that these supplements are important for the growth of other anaerobes, including P. melaninogenica (Gibbons and MacDonald, 1960; Summanen et al., 1993).

\section{Morphology}

Three species Porphyromonas gingivalis, Porphyromonas asaccharolytica and Porphyromonas endodontalis are found in human (Shah and Collins, 1988). Periodontitis of animal consist of Porphyromonas cangingivalis and Porphyromonas cansulci (Collins et al., 1994), Porphyromonas gingivicanis and Porphyromonas crevioricanis (Hirasawa and Takada, 1994), Porphyromonas canoris (Love et al., 1994), Porphyromonas gulae sp. Nov (Allaker et al., 1997a, b) and $P$. gingivalis.

It is strictly anaerobic, asaccharolytic or weakly saccharolytic, gram-negative, nonspore-forming and non-motile rod-shaped chemo-organotrophs.

On blood agar colonies shows brown to black pigments. All produce virulence factors such as collagenase, protease, and cytotoxin (Grenier and Mayrand, 1987).

\section{Less commonly encountered microbes}

The bacteria present in animal bite are CDC group EF-4b (from dog and large feline bite) or Comamonas spp from large feline bite wounds (Griego et al., 1995; Aghababian and Conte Jr., 1980; Goldstein, 1992).

CDC group EF-4b classified as eugonic fermenter group 4 (EF-4), is a nonfermentative, Gram negative coccoid to short rod bacteria (Schreckenberger and von Graevenitz, 1999). Comamonas spp are ubiquitous in environmental. It is gram negative bacilli that have generally been considered as non-pathogenic (Gilligan and Whittier, 1999).

In today world due to globalization and increasing trend of keeping exotic pets as companion to human, the chances of transmission of zoonotic diseases have increased. But major problem faced by public health workers is beyond this. There is tremendous rise in the population of elderly people and immune-compromised persons, who are at higher risk of getting infected. As such clinicians must be aware of potential of animal bite origin emerging microbial pathogens and its treatment. Thus more complete understanding of the circumstances of bites is needed in order to prevent and avoid infection in high risk groups.

\section{References}

Abrahamian, F.M. and E.J.C. Goldstein, 2004. Bites. In: Infectious Diseases, Gorbach, S.L., J.G. Bartlett and N.R. Blacklow (Eds.). $3^{\text {rd }}$ Edn., Lippincott, Williams and Wilkins, Philadelphia, PA.

Aghababian, R.V. and J.E. Conte Jr., 1980. Mammalian bite wounds. Ann. Emerg. Med., 9: 79-83.

Allaker, R.P., K.A. Young, T. Langlois, R. de Rosayro and J.M. Hardie, 1997b. Dental plaque flora of the dog with reference to 
fastidious and anaerobic bacteria associated with bites. J. Vet. Dent., 14: 127-130.

Allaker, R.P., R. de Rosayro, K.A. Young and J.M. Hardie, 1997a. Prevalence of Porphyromonas and Prevotella species in the dental plaque of dogs. Vet. Rec., 140: 147148.

August, J.R., 1988. Cat-scratch disease: Zoonosis update. J. Am. Vet. Med. Assoc., 193: 312315.

Benson, L.S., S.L. Edwards, A.P. Schiff, C.S. Williams and J.L. Visotsky, 2006. Dog and cat bites to the hand: Treatment and cost assessment. J. Hand Surg., 31: 468-473.

Bobo, R.A. and E.J. Newton, 1976. A previously undescribed gram-negative bacillus causing septicemia and meningitis. Am. J. Clin. Pathol., 65: 564-569.

Botha, W.C., P.J. Jooste and C.J. Hugo, 1998. The incidence of Weeksella- and Bergeyella-like bacteria in the food environment. J. Applied Microbiol., 84: 349-356.

Bracis, R., K. Seibers and R.M. Julien, 1979. Meningitis caused by group II $\mathrm{J}$ following a dog bite. West J. Med., 131: 438-440.

Bradley, J.S., 2002. Bite-Wound Infections. In: Pediatric Infectious Diseases: Principles and Practices, Jenson, H.B. and R.S. Baltimore (Eds.). 2nd Edn., Chapter 49, Saunders, London, UK., ISBN-13: 9780721681214 , pp: 741-750.

Brenner, D.J., D.G. Hollis, G.R. Fanning and R.E. Weaver, 1989. Capnocytophaga canimorsus sp. Nov. (formerly CDC group DF-2), a cause of septicemia following $\operatorname{dog}$ bite and $C$. cynodegmisp. Nov., a cause of localized wound infection following dog bite. J. Clin. Microbiol., 27: 231-235.

Brogan, T.V., S.L. Bratton, M.D. Dowd and M.A. Hegenbarth, 1995. Severe dog bites in children. Pediatrics, 96: 947-950.

Brook, I., 2003. Microbiology and management of human and animal bite wound infections. Primary Care: Clin. Off. Pract., 30: 25-39.

Chambers, G.H. and J.F. Payne, 1969. Treatment of dog-bite wounds. Minn. Med., 52: 427-430.

Chhabra, M. and R.L. Ichhpujani, 2003. Animal bites: The current management guidelines. Indian J. Pediatr., 70: S11-S16.

Chomel, B.B., 1993. The modern epidemiological aspects of rabies in the world. Comp.
Immunol. Microbiol. Infect. Dis., 16: 11-20.

Citron, D.M., S.H. Gerardo, M.C. Claros, F. Abrahamian, D. Talan and E.J.C. Goldstein, 1996. Incidence and characterization of Porphyromonas species isolated from infected dog and cat bite wounds in humans by biochemical tests and PCR fingerprinting. Clin. Infect. Dis., 23: S78-S82.

Collins, M.D., D.N. Love, J. Karjalainen, A. Kanervo and B. Forsblom et al., 1994. Phylogenetic analysis of members of the genus Porphyromonas and description of Porphyromonas cangingivalis $\mathrm{sp}$. nov. and Porphyromonas cansulci sp. nov. Int. J. Syst. Evol. Microbiol., 44: 674-679.

De Cadore, F., L. Joubert, A.R. Prevot and P. Tardieux, 1956. Studies on Fusiformis nucleates (Knorr) and its pathogenicity for humans and animals. Ann. Inst. Pasteur. (Paris), 91: 787-798.

Decostere, A., L.A. Devriese, R. Ducatelle and F. Haesebrouck, 2002. Bergeyella (Weeksella) zoohelcum associated with respiratory disease in a cat. Vet. Rec., 151: 392-392.

Delpietro, H.A. and R.G. Russo, 1996. Ecological and epidemiologic aspects of the attacks by vampire bats and paralytic rabies in Argentina and analysis of the proposals carried out for their control. Rev. Sci. Tech., 15: 971-984.

Dutta, J.K., 1998. Rabies transmission by oral and other non-bite routes. J. Indian Med. Assoc., 96: 359-359.

Dzink, J.L., S.S. Socransky and A.D. Haffajee, 1988. The predominant cultivable microbiota of active and inactive lesions of destructive periodontal diseases. J. Clin. Periodontol., 15: 316-323.

Edwards, M.S., 2004. Animal Bites. In: Textbook of Pediatric Infectious Diseases, Feigin, R.D., J.D. Cherry, G.J. Demmler and S.L. Kaplan (Eds.). 5th Edn., Saunders, Philadelphia, PA., ISBN-13: 9780721693293.

Eng, T.R. and D.B. Fishbein, 1990. Epidemiologic factors, clinical findings and vaccination status of rabies in cats and dogs in the United States in 1988: National Study Group on Rabies. J. Am. Vet. Med. Assoc., 197: 201-209.

Fischer, L.J., R.S. Weyant, E.H. White and F.D. Quinn, 1995. Intracellular multiplication and toxic destruction of cultured macrophages by 
Capnocytophagacanimorsus.

Infect. Immunity, 63: 3484-3490.

Gabel, C.L. and S.G. Gerberich, 2002. Risk factors for injury among veterinarians. Epidemiology, 13: 80-86.

Gibbons, R.J. and J.B. MacDonald, 1960. Hemin and vitamin $\mathrm{K}$ compounds as required factors for the cultivation of certain strains of Bacteroides melaninogenicus. J. Bacteriol., 80: 164-170.

Gilligan, P.H. and S. Whittier, 1999. Burkholderia, Stenotrophomonas, Ralstonia, Brevundimonas, Comamonas and Acidovorax. In: Manual of Clinical Microbiology, Murray, P.R., E.J. Baron, M.A. Pfaller, F.C. Tenover and R.H. Yolken (Eds.). 7th Edn., ASM Press, Washington DC., USA., pp: 526-538.

Goldstein, E.J., 1992. Bite wounds and infection. Clin. Infect. Dis., 14: 633-638.

Goldstein, E.J., 1994. Selected nonsurgical anaerobic infections: Therapeutic choices and the effective armamentarium. Clin. Infect. Dis., 18: S273-S279.

Goldstein, E.J., D.M. Citron and C.V. Merriam, 1999. Linezolid activity compared to those of selected macrolides and other agents against aerobic and anaerobic pathogens isolated from soft tissue bite infections in humans. Antimicrob. Agents Chemother., 43: 14691474.

Goldstein, E.J., D.M. Citron and G.A. Richwald, 1988. Lack of in vitro efficacy of oral forms of certain cephalosporins, erythromycin and oxacillin against Pasteurella multocida. Antimicrob. Agents Chemother., 32: 213-215.

Goldstein, E.J., D.M. Citron, B. Wield, U. Blachman, V.L. Sutter, T.A. Miller and S.M. Finegold, 1978. Bacteriology of human and animal bite wounds. J. Clin. Microbiol., 8: 667-672.

Greenberg, S.B., 1999. Serious waterborne and wilderness infections. Crit. Care Clin., 15: 387-414.

Grenier, D.A.N.I.E.L. and D.E.N.I.S. Mayrand, 1987. Selected characteristics of pathogenic and nonpathogenic strains of Bacteroides gingivalis. J. Clin. Microbiol., 25: 738-740.

Griego, R.D., T. Rosen, I.F. Orengo and J.E. Wolf, 1995. Dog, cat and human bites: A review. J. Am. Acad. Dermatol., 33: 10191029.
Grimault, E., J.C. Glerant, P. Aubry, G. Laurans, J.P. Poinsot and V. Jounieaux, 1996. Uncommon site of Bergeyella zoohelcum. Apropos of a case. Rev. Pneumol. Clin., 52: 387-389.

Hirasawa, M. and K. Takada, 1994. Porphyromonas gingivicanis sp. nov. and Porphyromonas crevioricanis sp. nov., isolated from beagles. Int. J. Syst. Evol. Mircobiol., 44: 637-640.

Holmes, B., A.G. Steigerwalt, R.E. Weaver and D.J. Brenner, 1986. Weeksellazoohelcumsp. nov. (formerly group IIj) from human clinical specimens. Syst. Applied Microbiol., 8: 191196.

Holt, J.G., N.R. Krieg, P.H. Sneath, J.T. Staley and S.T. Williams, 1994. Weeksella. In: Bergey's Manual of Determinative Bacteriology, Holt, J.G., N.R. Krieg, P.H. Sneath, J.T. Staley and S.T. Williams (Eds.). 9th Edn., Lippincott Williams and Wilkins, Baltimore, MD., ISBN-13: 9780683006032, pp: 99.

Holt, S.C., E.R. Leadbetter and S.S. Socransky, 1979. Capnocytophaga: New genus of gramnegative gliding bacteria. II. Morphology and ultrastructure. Arch. Microbiol., 122: 17-27.

Hore, C., 2001. Important unusual infections in Australia: A critical care perspective. Crit. Care Resuscitation, 3: 262-272.

Houff, S.A., R.C. Burton, R.W. Wilson, T.E. Henson and W.T. London et al.,., 1979. Human-to-human transmission of rabies virus by corneal transplant. N. Engl. J. Med., 300: 603-604.

Hsieh, S. and F.E. Babl, 1999. Serratia marcescens cellulitis following an iguana bite. Clin. Infect. Dis., 28: 1181-1182.

Iannelli, A. and G. Lupi, 2005. Penetrating brain injuries from a dog bite in an infant. Pediatr. Neurosurg., 41: 41-45.

Ichhpujani, R.L., C. Mala, M. Veena, J. Singh and M. Bhardwaj et al.,., 2008. Epidemiology of animal bites and rabies cases in India. A multicentric study. J. Communicable Dis., 40: 27-36.

Isotalo, P.A., D. Edgar and B. Toye, 2000. Polymicrobial tenosynovitis with Pasteurella multocida and other gram negative bacilli after a Siberian tiger bite. J. Clin. Pathol., 53: 871-872. 
Jolivet-Gougeon, A., A. Buffet, C. Dupuy, J.L. Sixou, M. Bonnaure-Mallet, S. David and M. Cormier, 2000. In vitro susceptibilities of capnocytophaga isolates to $\beta$-lactam antibiotics and $\beta$-lactamase inhibitors. Antimicrob. Agents Chemother., 44: 31863188

Jordan, E.F., M.B. Nye and A.E. Luque, 2006. Successful treatment of Pasteurella multocida meningitis with aztreonam. Scand. J. Infect. Dis., 38: 534-536.

Kaufman, A.F., K.R. Sulzer, A.G. Steigerwalt, F.C. Rogers and D.J. Brenner, 2005. Genomospecies serovar by serogroup. Centers for Disease Control and Prevention. [Cited 2005 Sep 8]. Available from http://www.pasteur.fr/recherche/Leptospira/St rains.html.

Kivinen, P.K., M.R. Lahtinen, E. Ruotsalainen, I.T. Harvima and M.L. Katila, 2003. Bergeyella zoohelcum septicaemia of a patient suffering from severe skin infection. Acta Dermatovenereologica Stockholm, 83: 74-75.

Kroes, I., P.W. Lepp and D.A. Relman, 1999. Bacterial diversity within the human subgingival crevice. Proc. Natl. Acad. Sci. USA., 96: 14547-14552.

Langley, R.L., W.H. Pryor and K.F. O'Brien, 1995. Health hazards among veterinarians: A survey and review. J. Agromedicine, 2: 23-52.

Leadbetter, E.R., S.C. Holt and S.S. Socransky, 1979. Capnocytophaga: New genus of gramnegative gliding bacteria I. General characteristics, taxonomic considerations and significance. Arch. Microbiol., 122: 9-16.

Lion, C., F. Escande and J.C. Burdin, 1996. Capnocytophaga canimorsus infections in human: Review of the literature and cases report. Eur. J. Epidemiol., 12: 521-533.

Love, D.N., J. Karjalainen, A. Kanervo, B. Forsblom and E. Sarkiala et al.,., 1994. Porphyromonas canoris sp. nov., an asaccharolytic, black-pigmented species from the gingival sulcus of dogs. Int. J. Syst. Evol. Mircobiol., 44: 204-208.

Mandell, G.L., J.E. Bennett and R. Dolin, 2005. Principles and Practice of Infectious Diseases. 6th Edn., Elsevier/Churchill Livingstone, Philadelphia, PA., Pages: 1726.

Mardy, C. and B. Holmes, 1988. Incidence of vaginal Weeksellavirosa (formerly group IIf).
J. Clin. Pathol., 41: 211-214.

Morris, J.T. and C.K. McAllister, 1992. Bacteremia due to Pasteurella multocida. Southern Med. J., 85: 442-443.

Murphey, D.K., E.J. Septimus and D.C. Waagner, 1992. Catfish-related injury and infection: Report of two cases and review of the literature. Clin. Infect. Dis., 14: 689-693.

Myers, J.P., 2003. Bite wound infections. Curr. Infect. Dis. Rep., 5: 416-425.

Newman, M.G., S.S. Socransky, E.D. Savitt, D.A. Propas and A. Crawford, 1976. Studies of the microbiology of periodontosis. J. Periodontol., 47: 373-379.

Nienhaus, A., C. Skudlik and A. Seidler, 2005. Work-related accidents and occupational diseases in veterinarians and their staff. Int. Arch. Occup. Environ. Health, 78: 230-238.

O'Neill, E., A. Moloney and M. Hickey, 2005. Pasteurella multocida meningitis: Case report and review of the literature. J. Infect., 50: 344345.

Park, K., 1994. Textbook of Prevention and Social Medicine. 14th Edn., Barnarsidas Bhanot Publishers, Jabalpur, India.

Pers, C., B. Gahrn-Hansen and W. Frederiksen, 1996. Capnocytophaga canimorsus septicemia in Denmark, 1982-1995: Review of 39 cases. Clin. Infect. Dis., 23: 71-75.

Pounder, D., 2003. Bat rabies. Br. Med. J., 326: 729-729.

Quinlan, K.P. and J.J. Sacks, 1999. Hospitalizations for dog bite injuries. J. Am. Med. Assoc., 281: 232-233.

Rehman, S.A., 1996. Country report on medical and veterinary aspects of rabies prevention and control: India from a veterinary perspective. Indian J. Community Health, 2: 20-30.

Reina, J. and N. Borrell, 1992. Leg abscess caused by Weeksellazoohelcum following a dog bite. Clin. Infect. Dis., 14: 1162-1163.

Rotivel, Y., M. Goudal, S. Wirth and H. Tsiang, 1998. Rabies is a risk for travelling children. Archives de Pediatrie, 5: 561-567.

Sacks, J.J., R. Lockwood, J. Hornreich and R.W. Sattin, 1996. Fatal dog attacks, 1989-1994. Pediatrics, 97: 891-895.

Schreckenberger, P.C. and A. von Graevenitz, 1999. Acinetobacter, Alcaligenes, Moraxella, Methylobacterium and other Non- 
Fermentative Gram-Negative Rods. In: Manual of Clinical Microbiology, Murray, P.R., E.J. Baron, M.A. Pfaller, F.C. Tenover and R.H. Yolken (Eds.). 7th Edn., ASM Press, Washington, DC., USA., pp: 539-560.

Sehgal, S., 1996. Medical and Veterinary aspects of rabies prevention and control in India. Ind. J. Comm. Health, 2: 18-19.

Shah, H.N. and M.D. Collins, 1988. Proposal for reclassification of Bacteroides asaccharolyticus, Bacteroides gingivalis and Bacteroides endodontalis in a new genus, Porphyromonas . Int. J. Syst. Bacteriol., 38: 128-131.

Sikes, R.K., 1962. Pathogenesis of rabies in wildlife. I. Comparative effect of varying doses of rabies virus inoculated into foxes and skunks. Am. J. Vet. Res., 23: 1041-1047.

Smith, P.F., A.M. Meadowcroft and D.B. May, 2000. Treating mammalian bite wounds. J. Clin. Pharm. Therapeut., 25: 85-99.

Socransky, S.S., S.C. Holt, E.R. Leadbetter, A.C.R. Tanner, E. Savitt and B.F. Hammond, 1979. Capnocytophaga: New genus of gramnegative gliding bacteria. III. Physiological characterization. Arch. Microbiol., 122: 29-33.

Sudarshan, M.K., 2005. Assessing burden of rabies in India: WHO sponsored national multicentric rabies survey, 2003. Indian J. Community Med., 30: 100-101.

Sudharshan, M.K., 1994. Is rabies under control in India. Indian J. Prev. Soc. Med., 25: 3-4.

Summanen, P., E.J. Baron, D.M. Citron, C.A. Strong, H.M. Wexler and S.M. Finegold, 1993. Wadsworth Anaerobic Bacteriology Manual. 5th Edn., Star Publishing Company, Belmont, Calif, pp: 39-48.

Talan, D.A., D.M. Citron, F.M. Abrahamian, G.J. Moran and E.J.C. Goldstein, 1999. Bacteriologic analysis of infected dog and cat bites. N. Engl. J. Med., 340: 85-92.

Valtonen, M., A. Lauhio, P. Carlson, J. Multanen, A. Sivonen, M. Vaara and J. Lahdevirta, 1995. Capnocytophaga canimorsus septicemia: Fifth report of a cat-associated infection and five other cases. Eur. J. Clin. Microbiol. Infect. Dis., 14: 520-523.

Vandamme, P., J.F. Bernardet, P. Segers, K. Kersters and B. Holmes, 1994. New perspectives in the classification of the flavobacteria: Description of Chryseobacterium gen. Nov., Bergeyella gen. Nov. and Empedobacter nom. rev. Int. J. Syst. Bacteriol., 44: 827-831.

Vandamme, P., M. Vancanneyt, A. van Belkum, P. Segers and W.G.V. Quint et al., 1996. Polyphasic analysis of strains of the genus Capnocytophaga and centers for disease control group DF-3. Int. J. Syst. Bacteriol., 46: 782-791.

Weber, D.J., J.S. Wolfson, M.N. Swartz and D.C. Hooper, 1984. Pasteurella multocida infections: Report of 34 cases and review of the literature. Medicine, 63: 133-151

Wienert, P., J. Heib, H. Rinecker and A. Sing, 1999. A human bite. Lancet, 354: 572-572.

Winkler, W.G., 1977. Human deaths induced by dog bites, United States, 1974-75. Public Health Rep., 92: 425-429.

Woo, P.C.Y., K.H.I. Ng, S.K.P. Lau, K.T. Yip and A.M.Y. Fung et al.,., 2003. Usefulness of the microseq $50016 \mathrm{~S}$ ribosomal DNA-based bacterial identification system for identification of clinically significant bacterial isolates with ambiguous biochemical profiles. J. Clin. Microbiol., 41: 1996-2001.

Woolfrey, B.F., C.O. Quall and R.T. Lally, 1985. Pasteurella multocida in an infected tiger bite. Arch. Pathol. Lab. Med., 108: 744-746.

\section{How to cite this article:}

Nitasha Sambyal, Ankush Proch, Inderpal Singh and Amit Challana. 2019. Animal Bite: Rabies and Beyond Rabies; A Review. Int.J.Curr.Microbiol.App.Sci. 8(08): 602-618. doi: https://doi.org/10.20546/ijcmas.2019.808.072 